\title{
Enhanced phosphatidylserine-selective cancer therapy with irradiation and SapC-DOPS nanovesicles
}

\author{
Harold W. Davis ${ }^{1}$, Subrahmanya D. Vallabhapurapu ${ }^{1}$, Zhengtao Chu ${ }^{1}$, Swarajya L. \\ Vallabhapurapu ${ }^{1}$, Robert S. Franco ${ }^{1}$, Michelle Mierzwa ${ }^{2}$, William Kassing ${ }^{2}$, William \\ L. Barrett ${ }^{2}$ and Xiaoyang $\mathbf{Q} \mathbf{i}^{1,3}$ \\ ${ }^{1}$ Division of Hematology/Oncology, Translational Research Laboratory, Department of Internal Medicine, University of \\ Cincinnati College of Medicine, Cincinnati, OH, USA \\ ${ }^{2}$ Department of Radiation Oncology, University of Cincinnati College of Medicine, Cincinnati, OH, USA \\ ${ }^{3}$ Division of Human Genetics, Department of Pediatrics, Cincinnati Children's Hospital Medical Center, Cincinnati, OH, USA \\ Correspondence to: Xiaoyang Qi, email: xiaoyang.qi@uc.edu
}

Keywords: radiotherapy-induced resistance; surface phosphatidylserine-selective; cancer cell death; SapC-DOPS nanovesicles; combined-treatment enhancement

Received: August 15, $2018 \quad$ Accepted: December 29, $2018 \quad$ Published: January 25, 2019

Copyright: Davis et al. This is an open-access article distributed under the terms of the Creative Commons Attribution License 3.0 (CC BY 3.0), which permits unrestricted use, distribution, and reproduction in any medium, provided the original author and source are credited.

\section{ABSTRACT}

Normal living cells exhibit phosphatidylserine (PS) primarily within the intracellular leaflet of the plasma membrane. In contrast, viable cancer cells have high levels of PS on the external surface, and exhibit a broad range of surface PS, even within specific types of cancer. Agents that target surface PS have recently been developed to treat tumors and are expected to be more effective with higher surface PS levels. In this context, we examined whether surface PS is increased with irradiation. In vitro irradiation of cancer cell lines selected surviving cells that had higher surface PS in a dose- and time-dependent manner. This was more pronounced if surface PS was initially in the lower range for cancer cells. Radiation also increased the surface PS of tumor cells in subcutaneous xenografts in nude mice. We found an inverse relationship between steady state surface PS level of cancer cell lines and their sensitivity to radiation-induced cell death. In addition, serial irradiation, which selected surviving cells with higher surface PS, also increased resistance to radiation and to some chemotherapeutic drugs, suggesting a PS-dependent mechanism for development of resistance to therapy. On the other hand, fractionated radiation enhanced the effect of a novel anti-cancer, PS-targeting drug, SapC-DOPS, in some cancer cell lines. Our data suggest that we can group cancer cells into cells with low surface PS, which are sensitive to radiation, and high surface PS, which are sensitive to SapC-DOPS. Combination of these interventions may provide a potential new combination therapy.

\section{INTRODUCTION}

Phospholipids are arranged asymmetrically in cell membranes with neutral phospholipids on the outer leaflet and anionic phospholipids [1] located primarily on the inside of the membrane [1-3]. An early event in apoptosis is the appearance of phosphatidylserine (PS) on the surface of the cell. This PS alerts phagocytic cells to engulf the cell and thus reduces the inflammatory response $[4,5]$. Elevated external PS is also found in non-apoptotic primary and metastatic cancer cells, and in their associated tumor vasculature [3, 6-8]. Furthermore, viable cancer cells with high external PS are resistant to phagocytemediated removal. Macrophages recognize PS on the surface of apoptotic cells [9] but cancer cells appear to repel macrophages by displaying CD47, which inhibits 
phagocytosis [10]. Recent studies have indicated that this surface PS may be exploited as a significant target for cancer therapy $[3,7,8]$. Indeed, the PS-targeting antibody, bavituximab [11], and the PS-binding peptide-peptoid hybrid, PPS1D1 [12], have been used successfully to trigger cytotoxicity of tumor-associated endothelial cells or cancer cells both in vitro and in vivo.

The loss of PS asymmetry in cancer cells may be due to reduced activity of ATP-dependent phospholipid translocases (flippases) and/or elevated activity of phospholipid scramblase, perhaps related to high levels of intracellular calcium $\left(\mathrm{Ca}^{2+}\right)[13,14]$. While cancer cells generally have higher amounts of PS on the surface, the amount varies greatly among cultured cell lines, even within the same class of cancer $[6,15]$. We have recently demonstrated that cancer cells with high external PS have reduced flippase activity and high $\mathrm{Ca}^{2+}$. compared to cancer cells with lower surface PS [14]. The high surface PS cells also have elevated total cellular PS [14]. Importantly, this increased PS is inducible and not associated with programmed cell death $[8,16]$.

Radiotherapy is a common treatment for malignant tumors and has been shown to improve outcomes when used with chemotherapy $[17,18]$. However, radiation can damage off target tissues and there is evidence that it can promote tumor growth by stimulating angiogenesis and cancer cell migration $[19,20]$. Interestingly, radiation increases surface PS on tumor blood vessels and this has been used successfully employed in mouse models of lung cancer and glioblastomas with the PS-targeting antibody, bavituximab [21-23]. While this work was aimed at the surface PS on endothelial cells we decided to examine the effects of radiation on tumor cell PS. SapC-DOPS, an anti-cancer protein/lipid nanovesicle developed in our laboratory targets surface PS and kills cancer cells both in vitro and in vivo $[6,11,24,25]$. SapC-DOPS is composed of the natural lysosomal protein, Saposin C (SapC), and dioleoylphosphatidylserine (DOPS) $[26,27]$ and a Phase 1 clinical trial has just been completed showing that SapC-DOPS is very safe [28]. We investigated whether radiation could alter surface PS of cancer cells. Since SapC-DOPS performs better with high surface PS cells $[6,15,29]$, we hypothesized that the high surface PS cells selected by irradiation may decrease the effects of subsequent irradiation or even chemotherapy but enhance susceptibility to SapC-DOPS treatment, thus introducing a potent new combination therapy.

\section{RESULTS}

We examined the effects of single and serial dose irradiation on the surface PS of a number of cancer cells. In the clinic, fractionated radiation therapy is often used to protect the patients from a single high dose radiation exposure [30-32]. Therefore, we serially irradiated cells at 5 Gy once a week for several weeks to investigate whether this would alter surface PS or modify the effects we obtained with a single dose of radiation.

\section{A single dose of irradiation increases the surface PS of cancer cells in vitro and in vivo}

cfPac-1, a pancreatic cancer cell line with moderate surface PS, exhibited a radiation dose dependent increase in PS $24 \mathrm{hr}$ after irradiation (Figure 1C). This increase in surface PS is on PI negative live cells as we detected very little cell death during the first 48 to 72 hours after the irradiation (even at $16 \mathrm{~Gy}$ ). Although cell lines varied in their response, radiation increased overall surface PS populations in all of the cancer cells that we tested except for PANC-1, which has a very high initial level of surface PS (Figures 1D and 1E). In contrast, HUVEC (human umbilical vein endothelial cells) and HPDE cells (a normal pancreatic epithelial cell line) had little or no increase in surface PS (Figure 1D). For all cancer and normal cell lines the percentage of dead cells was less than $10 \%$ and did not change significantly in the first $48 \mathrm{hr}$ following any of the radiation doses. The time dependency of PS change after irradiation was examined in several cancer cell lines, and an initial decrease was found before the increase (Figure 1F).

An increase in cell surface PS was also detected after irradiation of subcutaneous tumors formed after injection of cfPac-1 (Figure 1G) or NCI-H460 (Figure $1 \mathrm{H})$. Although there were variable numbers of dead cells associated with the tumors, this did not change appreciably with irradiation. For cfPac-1 the percentage of dead cells was $1.1 \pm 0.6$ and $2.7 \pm 0.8$ for control and irradiated cells, respectively; for NCI-H460 it was $72.0 \pm 15.0$ and 65.9 \pm 2.2 . All of the PS data shown are on live (propidium iodide negative) cells.

\section{The increase in surface PS after a single irradiation is dependent on caspase activity.}

The pan-caspase inhibitor, Z-VAD fmk, completely eliminated the radiation-induced surface PS elevation (Figure 2). On the other hand, as shown in Table 1, the activities of flippase and scramblase are unchanged in cfPac-1 cells during the period when the cells are still responding to the $10 \mathrm{~Gy}$ irradiation by increasing surface PS. While there is a slight, insignificant decrease in scramblase activity, we would expect an increase in this activity if scramblases were involved in the radiationinduced increase in surface PS. Total PS and intracellular calcium were also unchanged (Table 1).

\section{Cancer cell surface PS is correlated with sensitivity to a single dose of irradiation}

As presented in Figure 3 there is a positive correlation between surface PS on cancer cells and their 
resistance to a single dose of irradiation. In addition, the data show that the higher the dose of radiation, the stronger the correlation. Since irradiation selects for cells with higher surface PS it may make tumors less sensitive to future irradiation. Interestingly, these results suggest that the amount of surface PS on clinical specimens may be used as a marker to indicate whether the tumor will be sensitive to irradiation. In addition, we hypothesized that the increase in surface PS may make the tumors more susceptible to the PS-targeting drug SapC-DOPS.

\section{A single dose of irradiation has modest or no effect on SapC-DOPS-induced cell death}

Contrary to expectations, a single dose of $10 \mathrm{~Gy}$, although it increased the proportion of cells with higher surface PS (see Figure 1), did not enhance the cell killing ability of marginally effective doses of SapC-DOPS in either A2058 or cfPac-1 cells, and only showed modest augmentation in U87MG cells (Figure 4). This may be due to the increased surface PS that occurs at the early stages of apoptosis. Since these cells are already dying, additional cell death with SapC-DOPS would not be expected. There was also no improvement of SapC-DOPS activity in PANC-1 cells since they already had a high surface PS.

\section{Serial irradiation of cancer cell lines makes them less sensitive to subsequent radiation and to chemotherapeutic drugs but more sensitive to SapC-DOPS}

Since fractionated radiation therapy is a safe treatment regimen used routinely in the clinic, we performed serial irradiation of cells, weekly with 5 Gy for many weeks. During this time the cells were split every
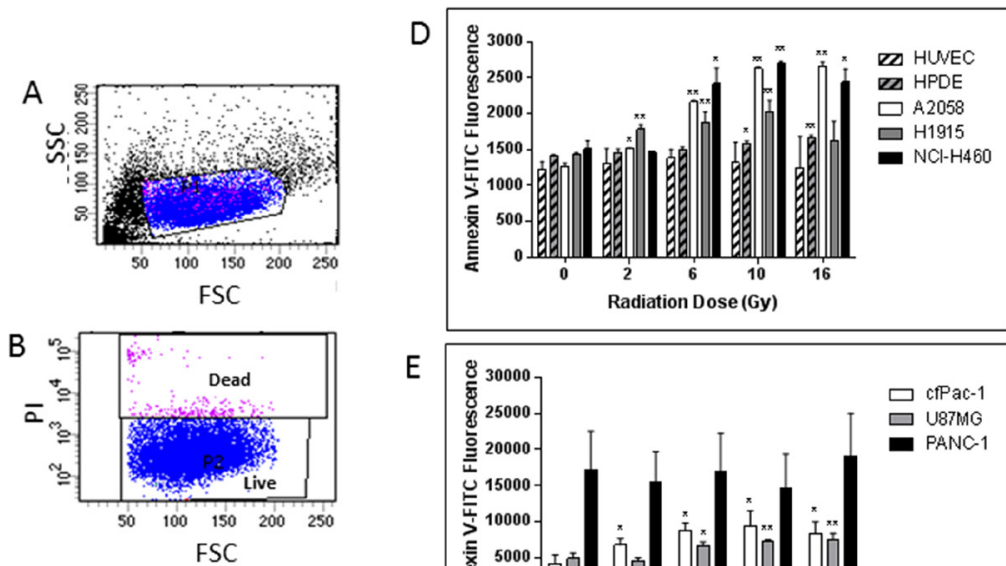

$\mathrm{E}$
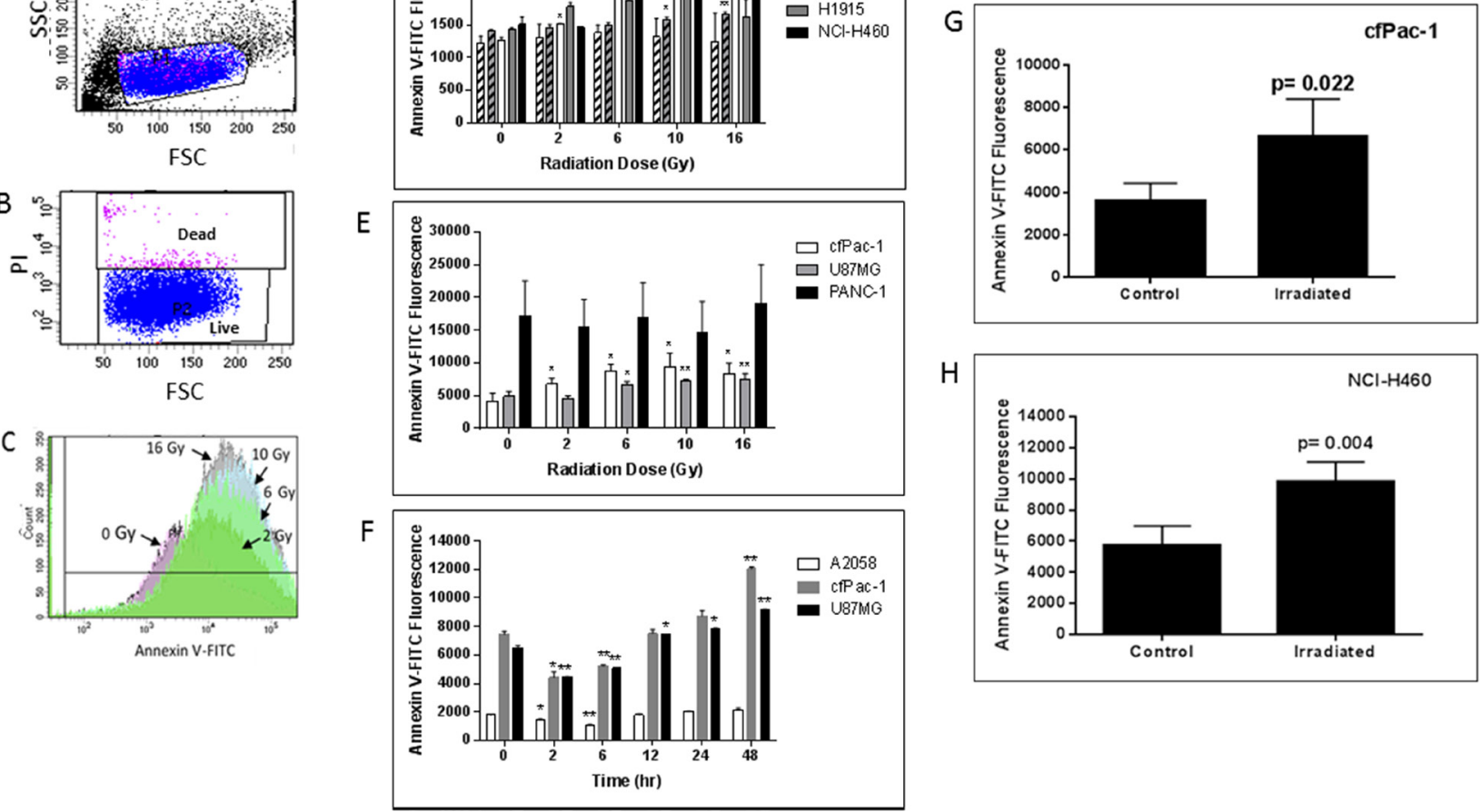

$\mathrm{H}$

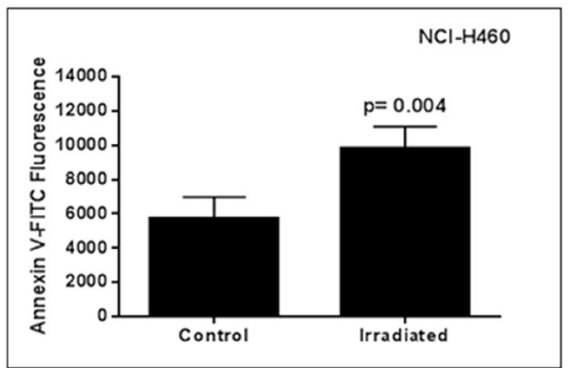

Figure 1: Radiation-induced increase in surface PS is dose- and time-dependent. (A-C) cfPac-1 cells, a human pancreatic cancer cell line, were irradiated at 0,2, 6, 10 and $16 \mathrm{~Gy}$. $24 \mathrm{hr}$ later Annexin V-FITC staining was performed and the cells were processed by flow cytometry. (A) Gating of cells. FSC: forward light scattering, an indication of cell volume; SSC: side light scattering, an indication of cellular granularity. (B) Gating of live cells. PI (propidium iodide) stains only dead cells. (C) Histogram of cells stained with Annexin V-FITC shows the effects of increasing doses of radiation on Annexin V staining (i.e. surface PS). (D-H) Cells were irradiated at the indicated doses and $24 \mathrm{hr}$ later Annexin V-FITC staining was determined on low surface PS cells (less than 2000 fluorescent units; (D) or moderate or high surface PS cells (greater than 3000 fluorescent units; (E). (F) Cells were irratiated at 5 Gy and analyzed at the indicated times (A2058, cfPac-1 and U87MG). To examine whether tumor cell surface PS was also increased by radiation $2 \times 10^{6} \mathrm{cfPac}-1$ (G) or NCI-H460 (H) cells were injected subcutaneously into nude mice. When the tumors were $\sim 400 \mathrm{~mm}^{3}$ some were treated with $10 \mathrm{~Gy}$ of targeted irradiation as described in "Materials and Methods". The tumors were removed $48 \mathrm{hr}$. later and the cells were dispersed into single cells. The cells in all panels were then processed and gated as in Figure $1 .{ }^{*} p<0.05,{ }^{* *} p<0.01$. cfPac-1 and PANC-1 are pancreatic cancer cell lines; A2058 is a melanoma cell line; NCI-H460 and H1915 are metastatic lung cancer cell lines; U87MG is a glioblastoma cell line, HPDE is a normal, immortalized pancreatic cell line and HUVEC are primary human umbilical vein endothelial cells. 
Table 1: The increase in surface PS caused by irradiation is unclear but does not appear to be due changes in intracellular calcium translocase activity or total PS

\begin{tabular}{lcccc}
\hline & Units & Control & Irradiated (10Gy) \\
\hline Flippase & Initial rate & $2.03 \pm 0.02$ & $2.03 \pm 0.07$ & NS \\
Scramblase & Initial rate & $0.75 \pm 0.19$ & $0.33 \pm 0.40$ & NS \\
Total PS & PS/PI ratio & $7.50 \pm 2.57$ & $5.28 \pm 1.95$ & NS \\
Calcium & arbitrary fluorescence & $8717.3 \pm 421.8$ & $7245.5 \pm 777.1$ & NS \\
\hline
\end{tabular}

The activities of the PS translocases, flippase and scramblase, the total amount of PS and intracellular calcium were determined in cfPac-1 cells $24 \mathrm{hr}$. after 10 Gy irradiation as described in "Materials and Methods".

3-4 days. The cells were analyzed 4-7 days following the final irradiation (see Figure 5A). As shown in Figure 5B, the serially irradiated cells had significantly higher surface PS than non-irradiated cells. These cells became more resistant to a single subsequent dose of radiation (Figure 5C) or to chemotherapeutic drugs, i.e., gemcitabine, temozolomide and cisplatin (Figure 5D). However, quite interestingly, serially irradiated A2058 and U87MG became more susceptible to SapC-DOPS treatment (Figure 5E). cfPac-1 was very sensitive to SapC-DOPS to begin with and the serial irradiation did not significantly enhance this.

To determine whether serial irradiation also affected normal cells we used immortalized but non-transformed human pancreatic ductal epithelial cells (HPDE). Unlike cancer cells, following serial irradiation the HPDE cells became more sensitive to radiation and remain sensitive to chemotherapeutic drugs, although the surface PS did not change. Sensitivity to a very high dose of SapC-DOPS was only slightly increased after serial irradiation.

\section{Combination treatment with radiation and SapC-DOPS reduces tumor growth better than either therapeutic alone}

NCI-H460 cells injected into mice quickly form tumors. We selected doses of radiation (10 Gy) and SapCDOPS $(4 \mathrm{mg} / \mathrm{kg})$ that did not significantly attenuate tumor growth by themselves. However, when used in combination, there was a significant reduction in tumor size (Figure 6).

\section{DISCUSSION}

Radiotherapy is a common modality for a variety of cancers and may be used alone or in combination with surgery, chemotherapy, or both. The intent is that it will cure the cancer, either by eliminating the tumor, preventing metastasis or blocking recurrence. However, recent data suggest that, in some cases, the low doses given during fractionated radiotherapy may actually increase the growth

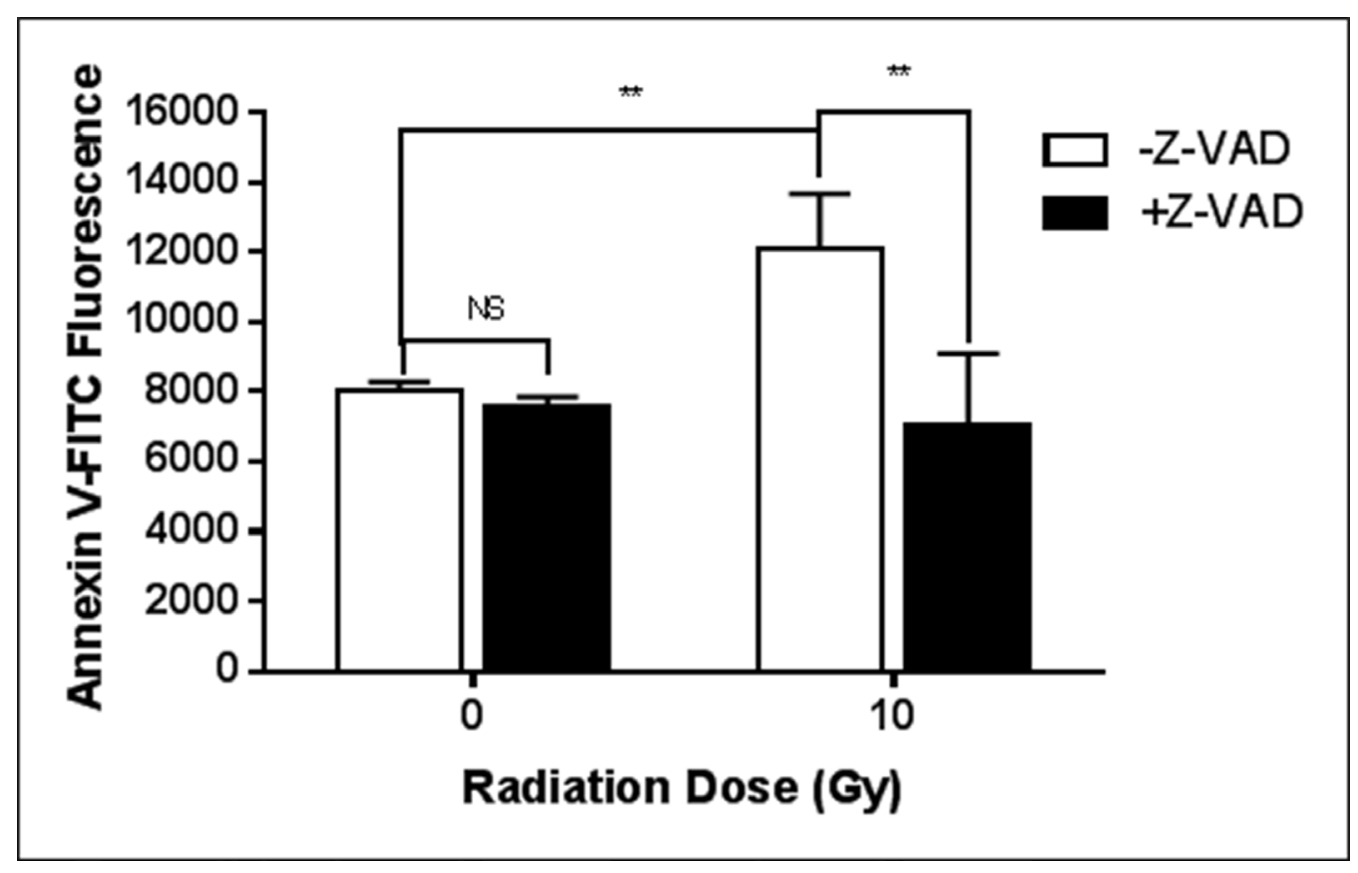

Figure 2: Caspase is critical for the radiation-induced exposure of PS. cfPac-1 cells were irradiated at 10 Gy in the presence or absence of $10 \mu \mathrm{M}$ Z-VAD-fmk, Sigma (St. Louis, MO, USA). $24 \mathrm{hr}$. later the cells were assessed for Annexin V binding as in Figure 1. ${ }^{* *} p<0.01, \mathrm{NS}=$ not significantly different from control. 
and metastasis of some tumors [19, 33] and make the cancer cell more resistant to subsequent doses of radiation [33-35]. Cancer cells and their attendant blood vessels in tumors have high surface PS compared to normal cells [3, 6-8] and a positive correlation between surface PS and malignancy has been demonstrated $[3,36]$. Herein we show that exposure to a single dose of irradiation induces a rapid and consistent externalization of PS in viable cancer cells with initially low to moderate surface PS both in vitro and in vivo. This increase in surface $\mathrm{PS}$ is both dose- and time-dependent and is on viable cells (non$\mathrm{PI}^{+}$) but probably reflects the early stages of apoptosis as Z-VAD fmk inhibited the increase in surface PS. Cell lines contain a mixture of low and high surface PS populations. While most of the cells remain viable and the cells that did die may have been populations with lower surface PS (see histogram of cells in Figure 1C). Indeed, we were able to serially irradiate cells weekly at 5 Gy for over a year (data not shown). After each irradiation some of the cells died but the average PS on the remaining viable cells was increased suggesting that the lower PS cells were dying so the radiation was selecting higher PS cells. Radiation has previously been shown to increase surface PS on tumor blood vessel cells, both in vitro [37] and in vivo [21-23] and to increase plasma PS [38]. This increased surface PS enhances the effects of the PS-targeting antibody, bavituximab, for triggering the death of tumor-associated endothelial cells and thus, the tumor [39]. We did not detect an increase in surface PS on endothelial cells in vitro but this may have been due to the type of endothelial cells, normal HUVEC versus the previously used brain tumor-derived bEnd 3 cells.

Flippases and scramblases are $\mathrm{Ca}^{2+}$ and ATPdependent aminophospholipid translocases that transport PS across the plasma membrane [40]. Flippases "flip" PS from the outside of the membrane to the inside while scramblases can transport PS in either direction. Flippases are inactivated during apoptosis while scramblases are stimulated. We have previously reported that the inherent high surface PS of cancer cells is due to reduced flippase activity probably triggered by high intracellular calcium [14]. The mechanism for the increase in surface PS in the irradiated cancer cells appears to be dependent on caspase activity as the pan-caspase inhibitor, Z-VAD fmk, completely eliminated the effect. While the caspasedependence suggests apoptosis, the cells were PI negative at this time and didn't show significant cell death until several days later. Radiation has previously been shown

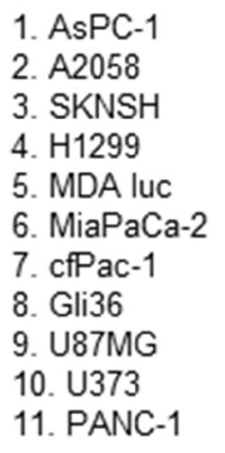

1. AsPC-1

2. A2058

3. SKNSH

4. $\mathrm{H} 1299$

5. MDA luc

6. $\mathrm{MiaPaCa}-2$

7. cfPac-1

8. Gli36

9. U87MG

11. PANC-1
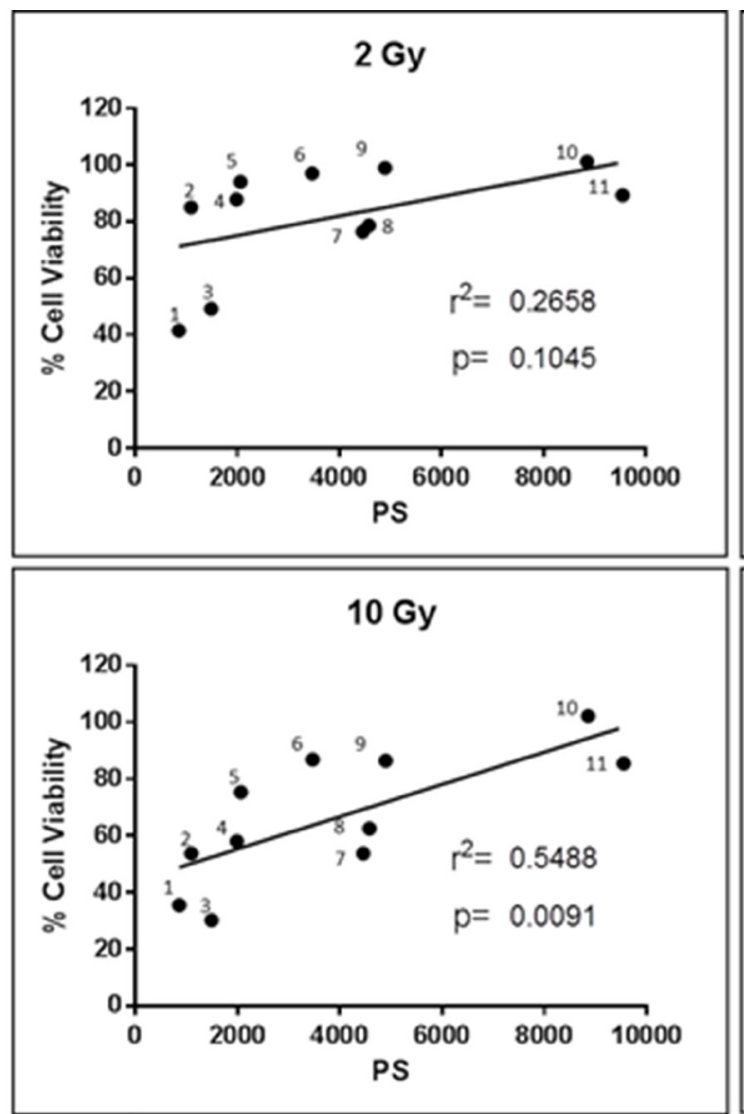

Figure 3: Correlation between cancer cell surface phosphatidylserine (PS) and resistance to radiation. Surface PS from untreated cells was determined with Annexin V-FITC staining and cell viability was ascertained with the MTT assay. Both assays are described in Materials and Methods. Each dot represents the average of two measurements. $\mathrm{r}^{2}$ and the $p$ values were calculated with GraphPad Prism 6 software. 
to increase caspase activity [41] and caspase can cleave and inactivate flippase [42, 43], which allows PS to accumulate on the exterior of the cell. Our data, however, indicate that the increase in surface PS is not due to a reduction in flippase activity or an increase in scramblase activity (Table 1). Although not significant, scramblase activity tended to decrease which is the opposite of what we would expect for an increase in surface PS [44]. An increase in intracellular calcium can also inhibit flippase [45] but this was unchanged with irradiation. Miyato et al. [46] have demonstrated that PS can induce apoptosis in $\mathrm{CHO}$ cells using a caspase other than the typical isozymes. This caspase is inhibited by Z-VAD-fmk, but is not caspase $1,3,8$ or 9 . It is possible that this unidentified caspase induces externalization of PS by a phospholipid translocase-independent mechanism. Finally, total PS, in comparison to other membrane phospholipids, although constitutively increased in cancer cells with high surface PS [14], was unaffected by radiation (Table 1).

As mentioned, surface PS is associated with greater malignancy $[3,36]$ and we show here, an
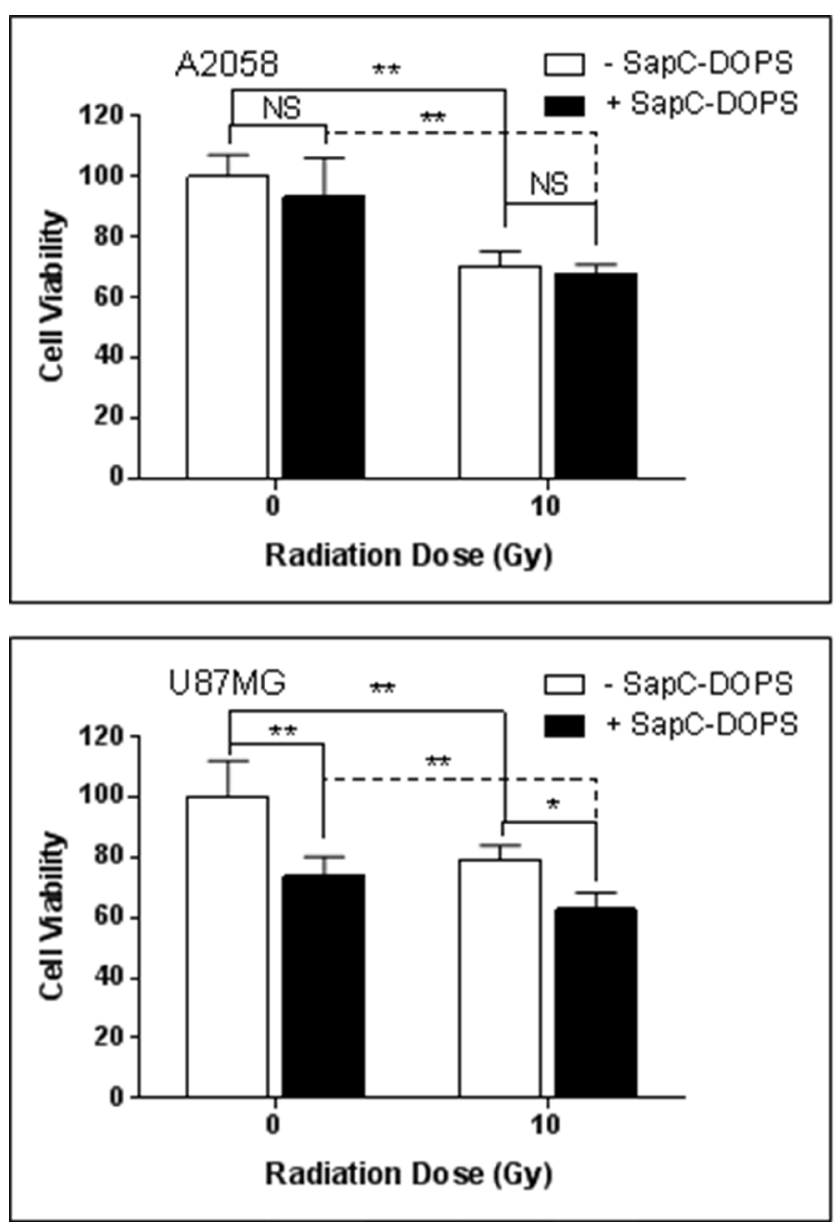

inverse relationship between cancer cell surface PS and sensitivity to radiation (Figure 4). On the other hand, our previous data indicate that cancer cells with elevated extracellular PS are more susceptible to SapC-DOPS [6, 15, 29]. Therefore, we hypothesized that SapC-DOPS could kill cells that are resistant to radiation and that radiation may actually enhance the performance of SapCDOPS.

The protein/lipid nanovesicle, SapC-DOPS shows a robust microscopic tumor-seeking activity in preclinical cancer models via a PS-mediated targeting pathway [15, 24, 29]. However, unlike most standard therapies, the nanovesicles are cytotoxic to cancer cells with diverse genetic profiles without induction of acquired resistance [6, 11]. We have previously demonstrated that SapC-DOPS synergizes with the chemotherapeutic drugs, temozolomide [47] and gemcitabine (unpublished data). However, a single dose of radiation $(10 \mathrm{~Gy}$ ) provided little or no enhancement of SapC-DOPS activity. We, therefore, examined the effects of serially irradiating the cells at 5 Gy weekly
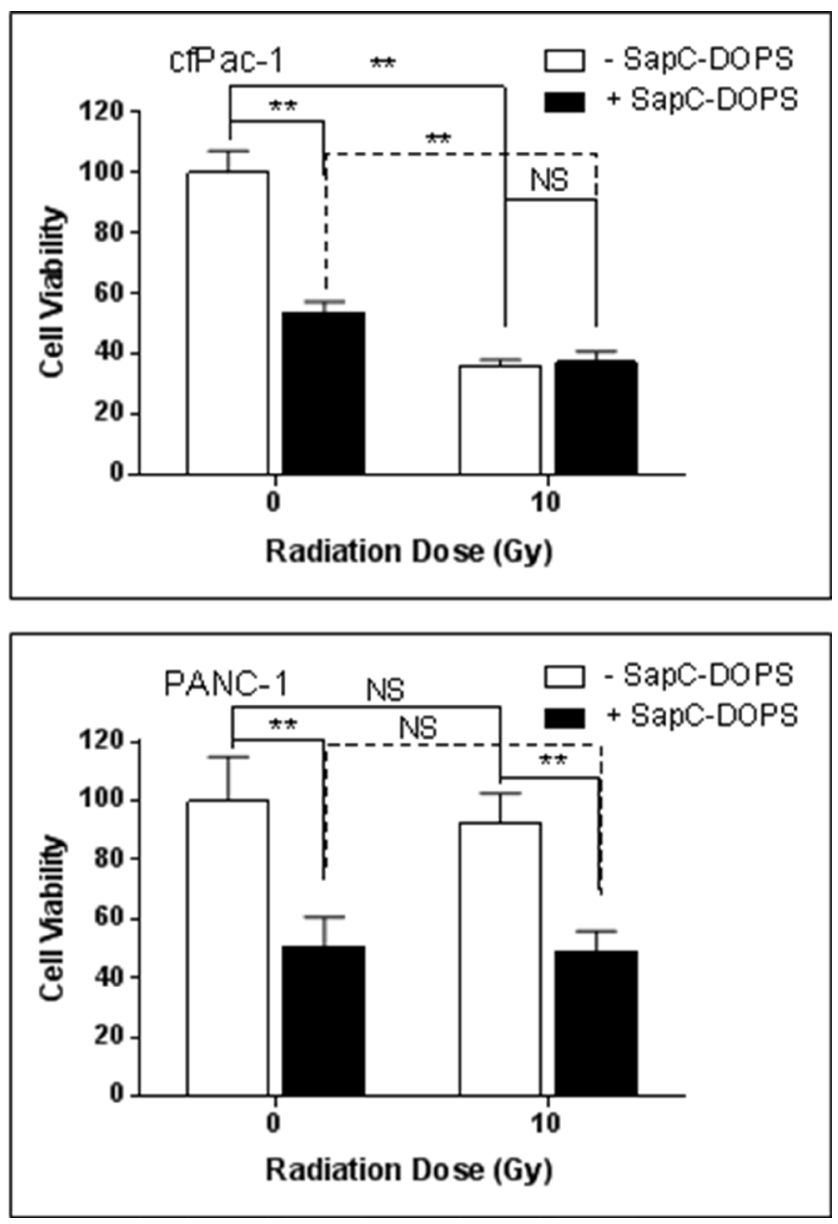

Figure 4: Single irradiation has modest or no effect on SapC-DOPS-induced cell death. Cells were irradiated at 10 Gy and 24 hours SapC-DOPS was added. Cell death was analyzed $72 \mathrm{hr}$. later with the MTT assay. The SapC-DOPS concentration was $25 \mu \mathrm{M}$ for A2058, cfPac-1 and PANC-1 but $40 \mu \mathrm{M}$ for U87MG. Shown is the $\%$ of live cells compared to the control (no irradiation, no SapC-DOPS) for each cell line. ${ }^{*} p<0.05,{ }^{* *} p<0.01, \mathrm{NS}=$ not significantly different from control. 
as described by Lee et al. [35]. Their data as well as ours (Figure 5C) and others [34] indicate that cancer cells become more resistant to radiation with repeated exposure to low dose radiation which is commonly used in fractionated treatment [48]. This increased resistance is accompanied by an increase in surface PS. Interestingly, serially irradiating cells also makes the cells more resistant to chemotherapeutic drugs. Although combining radiation with chemotherapy is standard practice $[17,18,49]$, there may be diminishing returns with multiple cycles of radiation treatment. Of course our in vitro data may not reflect clinical outcomes in patients.

Importantly, serial irradiation significantly improves SapC-DOPS efficacy depending on the cell line, with some cell lines responding much stronger to the sequential therapy compared to others - the one cell line that did not show the enhancement also had the least significant increase in PS. The surface PS of untreated U87MG cells is higher than A2058 or cfPac-1 even
A

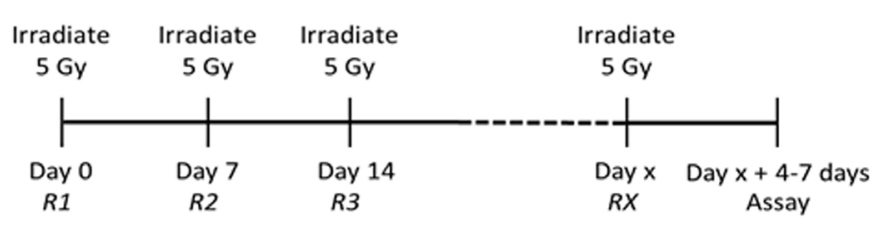

B

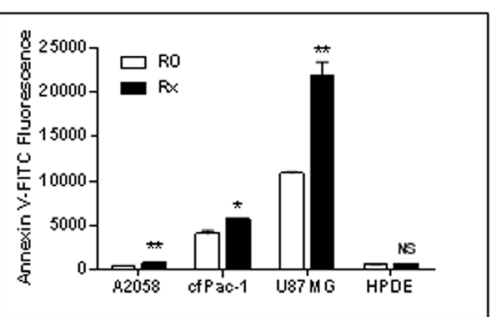

C

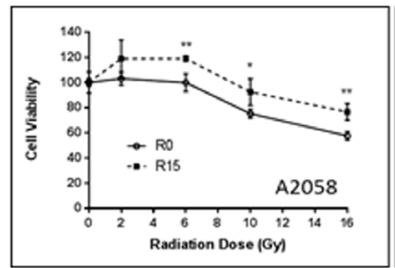

D

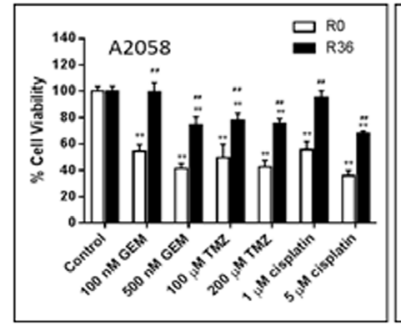

E

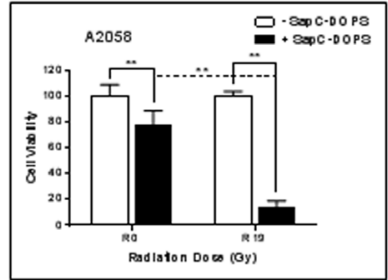

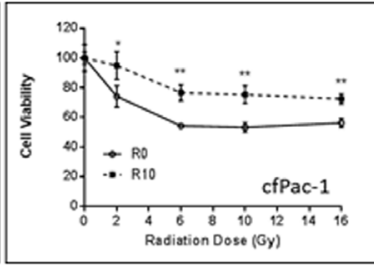
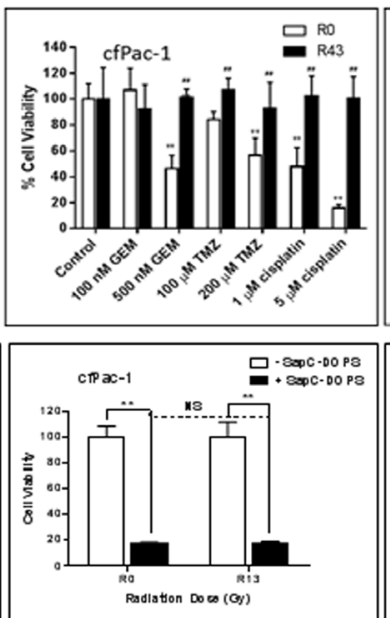
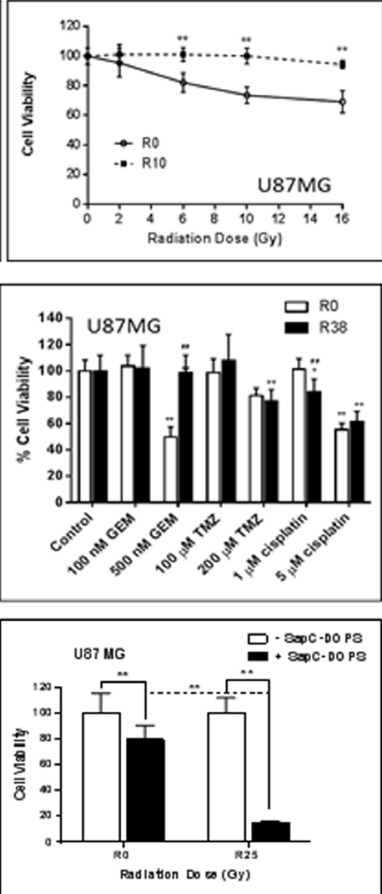
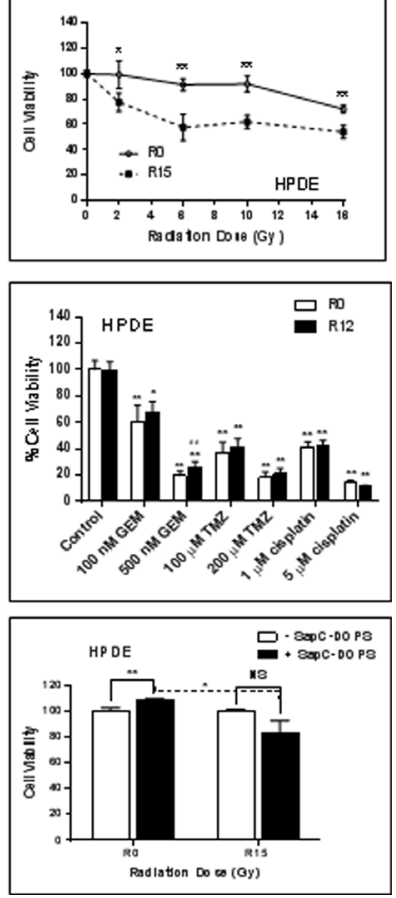

Figure 5: Serially irradiated cells maintain higher surface PS and are less sensitive to subsequent radiation exposure or the effects of chemotherapeutic drugs but are more sensitive to the effects of SapC-DOPS. A2058, cfPac-1, U87MG and HPDE were irradiated at 5 Gy every week for various numbers of weeks (the Rx is the number of weeks the cells were irradiated. Non serially-irradiated cells are designated R0. The media was changed immediately after the irradiation and the cells were split every 3-4 days. Treatments were given 4-7 days following the last 5 Gy irradiation, when the surface PS is still elevated, (A) Timeline of the treatment regime. (B) Surface PS was determined by Annexin V-FITC staining on Day 4 following the last 5 Gy irradiation. Rx; $x=15$ for A2058 and 10 for cfPac-1 and U87MG and 13 for HPDE. ${ }^{*} p<0.05,{ }^{* *} p<0.01$ compared to R0. Shown are the mean and S.D. (C-E) Cells were serially irradiated with $5 \mathrm{~Gy}$. (C) 7 days later they were exposed to the indicated doses of radiation and cell viability was determined by MTT assay was performed $72 \mathrm{hr}$. later. Shown is the $\%$ of live cells with $100 \%$ as the normalized control for each cell line. ${ }^{*} p<0.05,{ }^{* *} p<0.01$, compared to R0. (D) 7 days after the last 5 Gy irradiation, cells were treated with different doses of gemcitabine (GEM) temozolomide (TMZ) or cisplatin and cell viability was determined by MTT assay was performed $72 \mathrm{hr}$. later. ${ }^{*} p<0.05,{ }^{\#} p<0.01$, compared to R0 at the same dose of drug. (E) 7 days following the last 5 Gy irradiation, cells were treated with the indicated doses of SapC-DOPS (1 SapC:7 DOPS, Mol:Mol) and cell viability was determined by MTT assay was performed $72 \mathrm{hr}$. later. As in Figure 3, the SapC-DOPS concentration was $25 \mathrm{mM}$ for A2058 and cfPac-1, $40 \mathrm{mM}$ for U87MG and $50 \mathrm{mM}$ for HPDE. Shown are the \% of live cells with $100 \%$ as the normalized control for each cell line (as well as for the R0 and Rx). ${ }^{*} p<0.05,{ }^{* *} p<0.01$, NS = not significantly different. 
after the latter cell lines have been serially irradiated but U87MG is less sensitive to SapC-DOPS. U87MG is a glioblastoma cell line and we have previously shown that these tumor cells undergo lysosomal destabilization in response to SapC-DOPS instead of apoptosis as is seen in most other cancer cells [50]. Indeed our previous studies has shown that $\mathrm{U} 87 \mathrm{MG}$ are relatively resistant to SapC-DOPS compared to other cells with comparable surface PS so factors other than surface PS can apparently influence SapC-DOPS-induced cell killing. The saposin C of SapC-DOPS catabolizes sphingomyelin to ceramide [15], which is toxic to cells. Radiation also transiently increases ceramide $[51,52]$. Accordingly, multiple doses of radiation may increase ceramide above that obtained with a single dose and enough to enhance the SapC-DOPS effect. Sphingomyelin plays a role in the microenvironment of tumor cells and accelerates angiogenesis [53] so the breakdown of sphingomyelin may also provide a mechanism for this combination therapy.

Our data suggest that radiation targets low surface PS cells while SapC-DOPS works better on higher surface PS cells so a combination of these modalities would result in enhanced tumor cell death (see Schema 1) as we observed in cancer cells (Figure 5) and in mouse tumors (Figure 6). The improved efficacy of SapC-DOPS with fractionated irradiation may have significant benefits in the clinic as SapC-DOPS, which has shown no significant side effects in mice $[6,11$, 24], or so far in humans (27), may allow for a lower effective dose of radiation with fewer normal tissue toxicities.

\section{MATERIALS AND METHODS}

\section{Cell lines}

Human cancer cell lines, A2058, AsPC-1, SKNSH, MiaPaCa-2, cfPac-1, NCI-H460, H1915, H1299, U87MG and $\mathrm{U} 373$ and the normal pancreatic cell line (HPDE) were obtained from ATCC (Manassas, VA, USA). MDAMB-231-luc- were obtained from Caliper Life Sciences (Mountain View, CA, USA). HUVEC were from Lonza (Basel, Switzerland). HPDE, A2058, AsPC-1, MiaPaCa-2, cfPac-1, U87MG, Gli36 and U373 were cultured in DMEM (Fisher Scientific, Pittsburgh, PA, USA). H460, H1299 and H1915 were cultured in RPMI 1640 (Fisher Scientific). MDA-MB-231- Luc and SKNSH were cultured in AMEM (Invitrogen, Carlsbad, CA, USA). The above cell lines except HUVEC, were cultured in their respective media supplemented with $10 \%$ FBS and $1 \%$ Penicillin/Streptomycin. HUVEC were grown in EGM-2 media (Lonza).

\section{Flow cytometric analyses of annexin $\mathrm{V}$ binding}

Unless otherwise stated, cells at $60-80 \%$ confluency were irradiated and then, after the appropriate time, were trypsinized, resuspended in complete medium, spun down, and washed once with PBS then resuspended in annexin V staining buffer. Cells $\left(1 \times 10^{5}\right)$ were incubated at room temperature in the dark for 15 minutes in a final volume of $100 \mu \mathrm{l}$ containing $10 \mu \mathrm{l}$ Annexin V-FITC (Invitrogen, Carlsbad, CA, USA $</$ mark $>$ ) and $2 \mu \mathrm{g} / \mathrm{ml}$ propidium iodide (PI; BD-Pharmingen, Eugene, OR, USA). Annexin

\section{A}

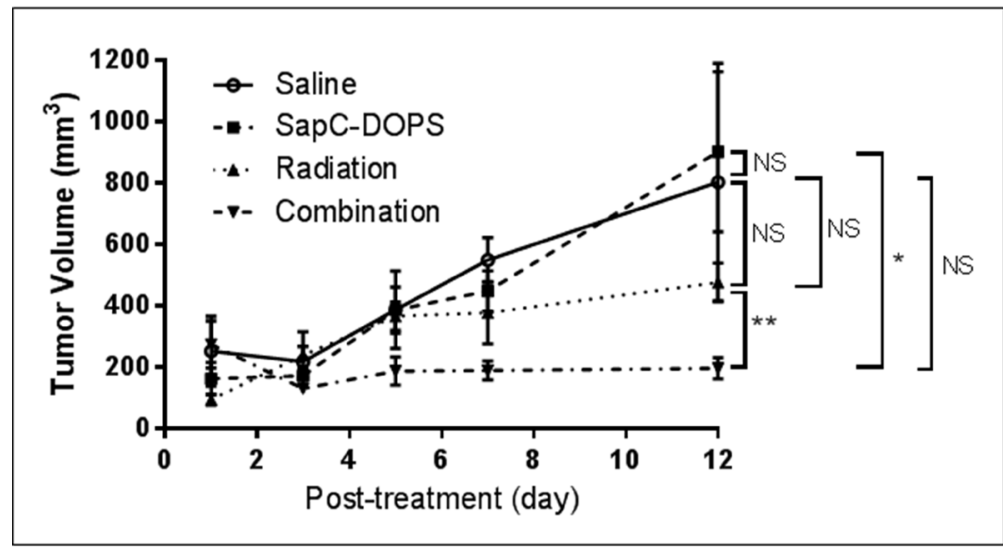

B

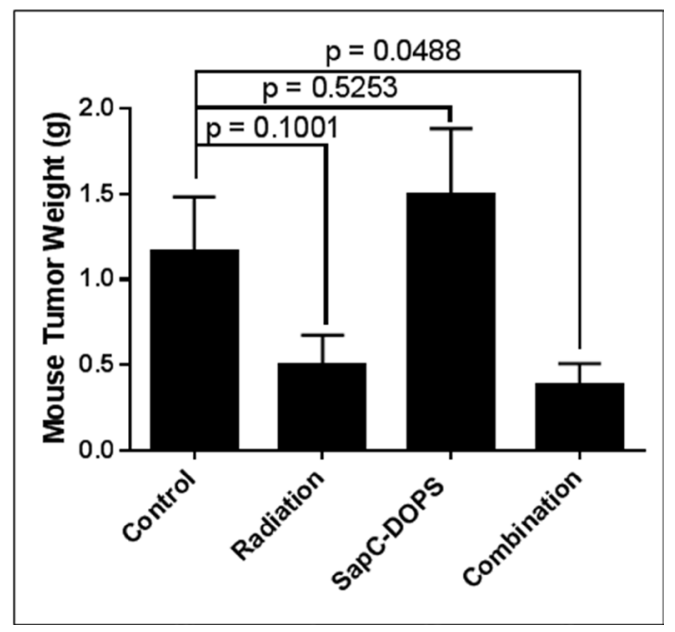

Figure 6: Combination of radiation and SapC-DOPS is more effective at reducing tumor size than either treatment alone. Mice were injected subcutaneously with $1 \times 10^{6} \mathrm{NCI}-\mathrm{H} 460$ cells. When tumors reached $\sim 100 \mathrm{~mm}^{3}$, the mice were irradiated at 10 Gy as in "Materials and Methods" on days 9 and 16 following injection of the cells. SapC-DOPS (4 mg SapC/kg) was injected via the tail vein on days $11,14,15,16,17$ and 18 . (A) Tumors were measured with calipers and volumes were calculated as $0.52 \times \mathrm{W} \times \mathrm{L} 2 \mathrm{where}$ $\mathrm{W}=$ width and $\mathrm{L}=$ length of the tumor. ${ }^{*} p<0.05,{ }^{* *} p<0.01, \mathrm{NS}=$ not significant. (B) The mice were euthanized on day 22 and the tumors were removed, rinsed with saline and weighed. $p$ values from $t$-tests are shown. $n=4-5$. 
V-FITC binding was measured by flow cytometry after adding $400 \mu \mathrm{l}$ of annexin $\mathrm{V}$ binding buffer, using a BD Fortessa. Data was analyzed with BD FACS Diva. For quantifying the annexin V-FITC signal from living cells, PI positive dead cells were gated out and the annexin V-FITC signal was obtained from PI negative forward scattered cells.

\section{Cell viability assay}

Cells were seeded in flat bottom 96 well plates (Falcon, Becton Dickson Labware, Franklin Lakes, NJ, USA) at 2000-12000 cells/per well (depending on the growth rate of the cell line). The number of cells seeded was adjusted to give an optical density of 0.6 to 1.2 (linear range of the assay) at the time of testing. The next day the cells were treated and $72 \mathrm{hr}$. later were analyzed for cell viability with the Cell Proliferation Kit I (MTT; Roche Diagnostics, Mannheim, Germany).

\section{Flippase and scramblase assays}

Flippase was measured as previously described [14]. Briefly, cells were resuspended in $3 \mathrm{ml}$ of flippase assay buffer and NBD-PS (Avanti Polar Lipids) was added to a final concentration of $3 \mu \mathrm{M}$. Cells with NBD-PS were divided into aliquots and incubated for $0,1,5,15,30$ or 45 minutes. After each incubation time, half of the cell suspension was separated for non-extracted sample and kept on ice. The remaining half was spun down to remove non inserted NBD-PS and subjected to BSA extraction of NBD-PS from the outer leaflet by adding 3\% fatty acid

\section{Cancer cells}

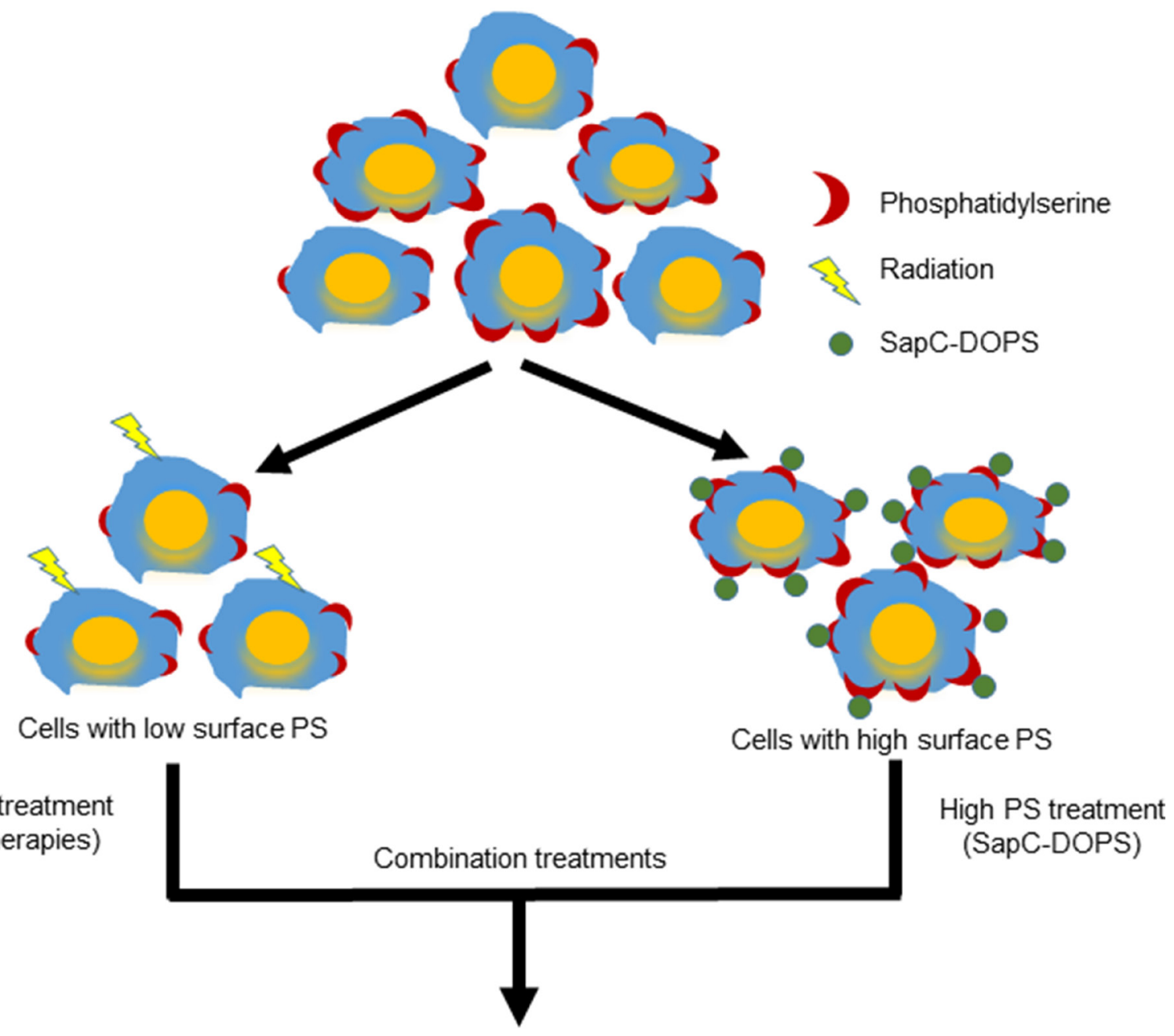

\section{Enhanced cancer cell death Reduced radio- and chemo-resistance}

Schema 1: Phosphatidylserine-selected therapies of SapC-DOPS nanovesicles and radiation to enhance cancer cell death. 
free BSA (MP Biomedicals) in flippase assay buffer. After incubation on ice for 20 minutes, freshly prepared sodium dithionite (Sigma) was added to a final concentration of $10 \mathrm{mM}$ and incubated a further 10 minutes, to reduce the NBD lipids in the outer cell surface. The cells were spun down and resuspended in flippase assay buffer containing $0.25 \% \mathrm{BSA}$ and $2 \mu \mathrm{g} / \mathrm{ml}$ PI. NBD-PS signal from unextracted and extracted samples was measured by flow cytometry from living cells after exclusion of PI-positive dead cells, using a BD Fortessa. Non-extractable NBDPS in the BSA and sodium dithionite treated sample was presented as the percentage of total amount in the control unextracted sample. Scramblase was measured in the same way but with NBD-PC (Avanti Polar Lipids).

\section{Measurement of intracellular calcium}

Intracellular calcium was measured by using the calcium binding dye Fluo-3 AM (Invitrogen). Cells $(1 \times$ 10s) were loaded with $5 \mu \mathrm{M}$ final concentration of Fluo-3 $\mathrm{AM}$ and incubated for $30 \mathrm{~min}$ at $37^{\circ} \mathrm{C}$. Cells were washed twice with DMEM, and resuspended in DMEM and incubated for a further 30 minutes at $37^{\circ} \mathrm{C}$. The cells were washed twice with PBS $+2 \%$ FBS and resuspended in 400 $\mathrm{ml}$ of this. Two $\mu \mathrm{g} / \mathrm{ml}$ PI was added and the Fluo-3 AM signal was measured by flow cytometry after exclusion of PI positive dead cells, using a BD Fortessa cytometer. Data was analyzed using BD FACS Diva software.

\section{Thin layer chromatography (TLC) and quantification of total phosphatidylserine}

Total cellular lipids were extracted by chloroform/ methanol extraction. TLC was performed as previously described [14]. Lipids were loaded onto a TLC plate based on protein quantification. Brain PS (Avanti Polar Lipids) and sphingomyelin (Matreya LLC) were run as molecular standards. Bands corresponding to PS were scraped and subjected to phosphorus extraction by acidic digestion. The liberated phosphorus was estimated by allowing a complex formation with ammonium molybdate (Sigma) and malachite green (Sigma) and by measuring the absorption at $660 \mathrm{~nm}$ [54]. Phosphorus was quantified using a standard curve obtained from phosphorus liberated from known concentrations of brain PS run on TLC plate. Cellular PS was expressed as the ratio of phosphorus obtained from PS and phosphorus obtained from total phospholipids. Additionally, PS was estimated by acquiring TLC band intensities of PS and sphingomyelin, using Image Studio Lite software; variations in PS are shown as a ratio of PS to sphingomyelin bands.

\section{Tumor growth in mice}

All animal studies were approved by the Institutional Animal Care and Use Committee of the University of Cincinnati (Protocol Number: 11-05-05-02). Female nude/nude athymic mice (Taconic Farms, Germantown, NY, USA) weighting approximately 20-25 g were injected with cancer cells $\left(1-2 \times 10^{6}\right.$ cells in $\left.0.2 \mathrm{ml} \mathrm{PBS}\right)$ subcutaneously in the right shoulder or flank. When the tumors were approximately $400 \mathrm{~mm}^{3}$, they were irradiated with targeted radiation as below. After $48 \mathrm{hr}$. the tumors were removed, dissected, and dissociated from a $30 \mathrm{mg}$ portion with a kit from 101Bio (Palo Alto, CA, USA). The harvested cells were stained with Annexin V-FITC and PI and subjected to flow cytometry. In other experiments, mice were treated with SapC-DOPS (prepared as in Chu et al. [6]) following the irradiation and the tumor sizes were measured for up to 15 days.

To examine radiation and SapC-DOPS on tumor growth, mice were injected with $1 \times 10^{6} \mathrm{NCI}-\mathrm{H} 460$ cells. When the tumors reached $100 \mathrm{~mm}^{3}$ the mice were treated with 10 Gy irradiation and/or $4 \mathrm{mg} / \mathrm{kg}$ SapC-DOPS. At the end of the experiment the tumors were removed and weighed.

\section{Irradiation}

Cells were grown to $60-80 \%$ confluency in 60 $\mathrm{mm}$ dishes then exposed to $\left({ }^{137} \mathrm{Cs}\right)$ irradiation with a GammaCell 40 Exactor (Nordion International) at doses of $0,2,6,10$ or $16 \mathrm{~Gy}$. The media was changed and the cells were processed for surface PS determination at the indicated times. Mice were irradiated at $10 \mathrm{~Gy}$ with an Xstrahl D3100 superficial systems (at $100 \mathrm{kV}$ ) with $2 \mathrm{~cm}$ cone and projected $1 \mathrm{~cm}$ deep.

\section{Statistical analyses}

Differences between treatment groups were determined by t-test, Pearson correlations were obtained with GraphPad Prism and data are presented as mean \pm standard deviation.

\section{Abbreviations}

PS: Phosphatidylserine; SapC: saposin C; DOPS: dioleoylphosphatidylserine; $\mathrm{Ca}^{2+}$ : intracellular calcium.

\section{Author contributions}

HWD, XQ designed the study. HWD, SDV, ZC, SLV performed the experiments and acquired data. HWD, XQ, SDV, RSF, MM, WK, WLB interpreted the results. HWD drafted the manuscript and XQ, SDV, RSF, MM, WK, WLB edited it. All Authors approved the final content for journal submission and publication. 


\section{ACKNOWLEDGMENTS}

We wish to thank Ken Null and the radiation technicians at Barrett Cancer Center for their help with irradiation the mice.

\section{CONFLICTS OF INTEREST}

$\mathrm{X}$. Qi is listed as an inventor on the patent for SapC-DOPS technology that is the subject of this research. Consistent with current Cincinnati Children's Hospital Medical Center policies, the development and commercialization of this technology has been licensed to Bexion Pharmaceuticals, LLC, in which Dr. Qi, holds a minor $(<5 \%)$ equity interest. The other authors declared no conflicts of interest.

\section{FUNDING}

Research Funds and Hematology-Oncology Programmatic Support from University of Cincinnati College of Medicine (to X. Qi), University of Cincinnati Bearcats Against Cancer Grant (to X. Qi), and New Drug State Key Project Grant Number 009ZX09102-205 (to X. Qi).

\section{REFERENCES}

1. Bevers EM, Williamson PL. Getting to the Outer Leaflet: Physiology of Phosphatidylserine Exposure at the Plasma Membrane. Physiol Rev. 2016; 96:605-45. https://doi. org/10.1152/physrev.00020.2015.

2. Connor J, Bucana C, Fidler IJ, Schroit AJ. Differentiationdependent expression of phosphatidylserine in mammalian plasma membranes: quantitative assessment of outer-leaflet lipid by prothrombinase complex formation. Proc Natl Acad Sci U S A. 1989; 86:3184-3188.

3. Riedl S, Rinner B, Asslaber M, Schaider H, Walzer S, Novak A, Lohner K, Zweytick D. In search of a novel target - phosphatidylserine exposed by non-apoptotic tumor cells and metastases of malignancies with poor treatment efficacy. Biochim Biophys Acta. 2011; 1808:2638-2645.

4. Huang X, Bennett M, Thorpe PE. A monoclonal antibody that binds anionic phospholipids on tumor blood vessels enhances the antitumor effect of docetaxel on human breast tumors in mice. Cancer Res. 2005; 65:4408-4416.

5. Huynh ML, Fadok VA, Henson PM. Phosphatidylserinedependent ingestion of apoptotic cells promotes TGF-beta1 secretion and the resolution of inflammation. J Clin Invest. 2002; 109:41-50.

6. Chu Z, Abu-Baker S, Palascak MB, Ahmad SA, Franco RS, Qi X. Targeting and cytotoxicity of SapC-DOPS nanovesicles in pancreatic cancer. PLoS One. 2013; 8:e75507.
7. Ran S, Downes A, Thorpe PE. Increased exposure of anionic phospholipids on the surface of tumor blood vessels. Cancer Res. 2002; 62:6132-6140.

8. Ran S, Thorpe PE. Phosphatidylserine is a marker of tumor vasculature and a potential target for cancer imaging and therapy. Int J Radiat Oncol Biol Phys. 2002; 54:1479-1484.

9. Poon IK, Lucas CD, Rossi AG, Ravichandran KS. Apoptotic cell clearance: basic biology and therapeutic potential. Nat Rev Immunol. 2014; 14:166-80.

10. Jaiswal S, Jamieson CH, Pang WW, Park CY, Chao MP, Majeti R, Traver D, van Rooijen N, Weissman IL. CD47 is upregulated on circulating hematopoietic stem cells and leukemia cells to avoid phagocytosis. Cell. 2009; 138:271-285.

11. Abu-Baker S, Chu Z, Stevens AM, Li J, Qi X. Cytotoxicity and Selectivity in Skin Cancer by SapC-DOPS Nanovesicles. J Cancer Ther. 2012; 3:321-326.

12. Desai TJ, Toombs JE, Minna JD, Brekken RA, Udugamasooriya DG. Identification of lipidphosphatidylserine (PS) as the target of unbiasedly selected cancer specific peptide-peptoid hybrid PPS1. Oncotarget. 2016; 7:30678-90. https://doi.org/10.18632/ oncotarget.8929.

13. Soupene E, Kemaladewi DU, Kuypers FA. ATP8A1 activity and phosphatidylserine transbilayer movement. J Receptor Ligand Channel Res. 2008; 1:1-10. https://doi.org/10.2147/ JRLCR.S3773.

14. Vallabhapurapu SD, Blanco VM, Sulaiman MK, Vallabhapurapu SL, Chu Z, Franco RS, Qi X. Variation in human cancer cell external phosphatidylserine is regulated by flippase activity and intracellular calcium. Oncotarget. 2015; 6:34375-88. https://doi.org/10.18632/ oncotarget.6045.

15. Qi X, Chu Z, Mahller YY, Stringer KF, Witte DP, Cripe TP. Cancer-selective targeting and cytotoxicity by liposomalcoupled lysosomal saposin C protein. Clin Cancer Res. 2009; 15:5840-5851.

16. Segawa K, Suzuki J, Nagata S. Constitutive exposure of phosphatidylserine on viable cells. Proc Natl Acad Sci U S A. $2011 ; 108: 19246-19251$.

17. Blackstock AW, Bernard SA, Richards F, Eagle KS, Case LD, Poole ME, Savage PD, Tepper JE, Phase I. Phase I trial of twice-weekly gemcitabine and concurrent radiation in patients with advanced pancreatic cancer. $\mathrm{J}$ Clin Oncol. 1999; 17:2208-12. https://doi.org/10.1200/ JCO.1999.17.7.2208.

18. Stupp R, Dietrich PY, Ostermann Kraljevic S, Pica A, Maillard I, Maeder P, Meuli R, Janzer R, Pizzolato G, Miralbell R, Porchet F, Regli L, de Tribolet N, et al. Promising survival for patients with newly diagnosed glioblastoma multiforme treated with concomitant radiation plus temozolomide followed by adjuvant temozolomide. J Clin Oncol. 2002; 20:1375-82. https://doi.org/10.1200/ JCO.2002.20.5.1375. 
19. Sofia Vala I, Martins LR, Imaizumi N, Nunes RJ, Rino J, Kuonen F, Carvalho LM, Rüegg C, Grillo IM, Barata JT, Mareel M, Santos SC. Low doses of ionizing radiation promote tumor growth and metastasis by enhancing angiogenesis. PLoS One. 2010; 5:e11222. https://doi. org/10.1371/journal.pone.0011222.

20. Madani I, De Neve W, Mareel M. Does ionizing $r$ adiation stimulate cancer invasion and metastasis? Bull Cancer. 2008; 95:292-300.

21. He J, Luster TA, Thorpe PE. Radiation-enhanced vascular targeting of human lung cancers in mice with a monoclonal antibody that binds anionic phospholipids. Clin Cancer Res. 2007; 13:5211-5218.

22. He J, Yin Y, Luster TA, Watkins L, Thorpe PE. Antiphosphatidylserine antibody combined with irradiation damages tumor blood vessels and induces tumor immunity in a rat model of glioblastoma. Clin Cancer Res. 2009; 15:6871-6880.

23. Saha D, Watkins L, Yin Y, Thorpe P, Story MD, Song K, Raghavan P, Timmerman R, Chen B, Minna JD, Solberg TD. An orthotopic lung tumor model for image-guided microirradiation in rats. Radiat Res. 2010; 174:62-71. https:// doi.org/10.1667/RR2157.1.

24. Blanco VM, Chu Z, Vallabhapurapu SD, Sulaiman MK, Kendler A, Rixe O, Warnick RE, Franco RS, Qi X. Phosphatidylserine-selective targeting and anticancer effects of SapC-DOPS nanovesicles on brain tumors. Oncotarget. 2014; 5:7105-18. https://doi.org/10.18632/oncotarget.2214.

25. Davis HW, Hussain N, Qi X. Detection of cancer cells using SapC-DOPS nanovesicles. Mol Cancer. 2016; 15:33. https://doi.org/10.1186/s12943-016-0519-1.

26. Qi X, Qin W, Sun Y, Kondoh K, Grabowski GA. Functional organization of saposin C. Definition of the neurotrophic and acid beta-glucosidase activation regions. J Biol Chem. 1996; 271:6874-6880.

27. Qi X, Chu Z. Fusogenic domain and lysines in saposin C. Arch Biochem Biophys. 2004; 424:210-218.

28. Wise-Draper TM, Moorthy G, Salkeni MA, Karim NA, Thomas HE, Mercer CA, Beg MS, O'Gara S, Olowokure O, Fathallah H, Kozma SC, Thomas G, Rixe O, et al. A Phase Ib Study of the Dual PI3K/mTOR Inhibitor Dactolisib (BEZ235) Combined with Everolimus in Patients with Advanced Solid Malignancies. Target Oncol. 2017; 12: 323-32. https://doi.org/10.1007/s11523-017-0482-9.

29. Zhao S, Chu Z, Blanco VM, Nie Y, Hou Y, Qi X. SapCDOPS nanovesicles as targeted therapy for lung cancer. Mol Cancer Ther. 2015; 14:491-498.

30. Brenner DJ, Martel MK, Hall EJ. Fractionated regimens for stereotactic radiotherapy of recurrent tumors in the brain. Int J Radiat Oncol Biol Phys. 1991; 21:819-24.

31. Werner-Wasik M, Rudoler S, Preston PE, Hauck WW, Downes BM, Leeper D, Andrews D, Corn BW, Curran WJ Jr. Immediate side effects of stereotactic radiotherapy and radiosurgery. Int J Radiat Oncol Biol Phys. 1999; 43:299-304.
32. Nagata Y, Takayama K, Matsuo Y, Norihisa Y, Mizowaki T, Sakamoto T, Sakamoto M, Mitsumori M, Shibuya K, Araki N, Yano S, Hiraoka M. Clinical outcomes of a phase I/II study of 48 Gy of stereotactic body radiotherapy in 4 fractions for primary lung cancer using a stereotactic body frame. Int J Radiat Oncol Biol Phys. 2005; 63:1427-31.

33. Malaise EP, Lambin P, Joiner MC, and Are There Some Clinical Implications. Radiosensitivity of human cell lines to small doses. Are there some clinical implications? Radiat Res. 1994; 138:S25-27. https://doi.org/10.2307/3578754.

34. Lambin P, Malaise EP, Joiner MC. Might intrinsic radioresistance of human tumour cells be induced by radiation? Int J Radiat Biol. 1996; 69:279-90. https://doi. org/10.1080/095530096145832.

35. Lee JU, Hosotani R, Wada M, Doi R, Kosiba T, Fujimoto K, Miyamoto Y, Tsuji S, Nakajima S, Nishimura Y, Imamura M. Role of Bcl-2 family proteins (Bax, Bcl-2 and Bcl-X) on cellular susceptibility to radiation in pancreatic cancer cells. Eur J Cancer. 1999; 35:1374-80.

36. Cichorek M, Kozłowska K, Witkowski JM, Zarzeczna M. Flow cytometric estimation of the plasma membrane diversity of transplantable melanomas, using annexin V. Folia Histochem Cytobiol. 2000; 38:41-43.

37. Zhao Z, Johnson MS, Chen B, Grace M, Ukath J, Lee VS, McRobb LS, Sedger LM, Stoodley MA. Live-cell imaging to detect phosphatidylserine externalization in brain endothelial cells exposed to ionizing radiation: implications for the treatment of brain arteriovenous malformations. J Neurosurg. 2016; 124:1780-87. https:// doi.org/10.3171/2015.4.JNS142129.

38. Wang C, Yang J, Nie J. Plasma phospholipid metabolic profiling and biomarkers of rats following radiation exposure based on liquid chromatography-mass spectrometry technique. Biomed Chromatogr. 2009; 23:1079-85. https:// doi.org/10.1002/bmc.1226.

39. Allen TM, Cullis PR. Drug delivery systems: entering the mainstream. Science. 2004; 303:1818-22. https://doi. org/10.1126/science.1095833.

40. Daleke DL. Phospholipid flippases. J Biol Chem. 2007; 282:821-825.

41. Marshman E, Ottewell PD, Potten CS, Watson AJ. Caspase activation during spontaneous and radiation-induced apoptosis in the murine intestine. J Pathol. 2001; 195:28592. https://doi.org/10.1002/path.967.

42. Segawa K, Kurata S, Yanagihashi Y, Brummelkamp TR, Matsuda F, Nagata S. Caspase-mediated cleavage of phospholipid flippase for apoptotic phosphatidylserine exposure. Science. 2014; 344:1164-68.

43. Mandal D, Moitra PK, Saha S, Basu J. Caspase 3 regulates phosphatidylserine externalization and phagocytosis of oxidatively stressed erythrocytes. FEBS Lett. 2002; 513:184-188.

44. Williamson P, Schlegel RA. Back and forth: the regulation and function of transbilayer phospholipid movement in eukaryotic cells. Mol Membr Biol. 1994; 11:199-216. 
45. Segawa K, Kurata S, Nagata S. Human Type IV P-type ATPases That Work as Plasma Membrane Phospholipid Flippases and Their Regulation by Caspase and Calcium. J Biol Chem. 2016; 291:762-772.

46. Miyato $\mathrm{Y}$, Ibuki Y, Ohyama H, Yamada T, Goto R. Phosphatidylserine induces apoptosis in $\mathrm{CHO}$ cells without mitochondrial dysfunction in a manner dependent on caspases other than caspases-1, -3, -8 and -9. FEBS Lett. 2001; 504:73-77.

47. Wojton J, Meisen WH, Jacob NK, Thorne AH, Hardcastle J, Denton N, Chu Z, Dmitrieva N, Marsh R, Van Meir EG, Kwon CH, Chakravarti A, Qi X, Kaur B. SapC-DOPSinduced lysosomal cell death synergizes with TMZ in glioblastoma. Oncotarget. 2014; 5:9703-09. https://doi. org/10.18632/oncotarget.2232.

48. Potters L, Steinberg M, Rose C, Timmerman R, Ryu S, Hevezi JM, Welsh J, Mehta M, Larson DA, Janjan NA, and American Society for Therapeutic Radiology and Oncology, and American College of Radiology. American Society for Therapeutic Radiology and Oncology and American College of Radiology practice guideline for the performance of stereotactic body radiation therapy. Int J Radiat Oncol Biol Phys. 2004; 60:1026-32. https://doi.org/10.1016/j. ijrobp.2004.07.701.

49. Chakravarti A, Winter K, Wu CL, Kaufman D, Hammond E, Parliament M, Tester W, Hagan M, Grignon D, Heney N, Pollack A, Sandler H, Shipley W. Expression of the epidermal growth factor $\mathrm{r}$ eceptor and Her-2 are predictors of favorable outcome and reduced complete response rates, respectively, in patients with muscle-invading bladder cancers treated by concurrent radiation and cisplatinbased chemotherapy: a report from the Radiation Therapy Oncology Group. Int J Radiat Oncol Biol Phys. 2005; 62:309-17. https://doi.org/10.1016/j.ijrobp.2004.09.047.

50. Wojton J, Chu Z, Mathsyaraja H, Meisen WH, Denton N, Kwon CH, Chow LM, Palascak M, Franco R, Bourdeau T, Thornton S, Ostrowski MC, Kaur B, Qi X. Systemic delivery of SapC-DOPS has antiangiogenic and antitumor effects against glioblastoma. Mol Ther. 2013; 21:1517-25. https://doi.org/10.1038/mt.2013.114.

51. Radford IR. Initiation of ionizing radiation-induced apoptosis: DNA damage-mediated or does ceramide have a role? Int J Radiat Biol. 1999; 75:521-28. https://doi. org/10.1080/095530099140168.

52. Kolesnick R, Fuks Z. Radiation and ceramide-induced apoptosis. Oncogene. 2003; 22:5897-5906.

53. Kim CW, Lee HM, Lee TH, Kang C, Kleinman HK, Gho YS. Extracellular membrane vesicles from tumor cells promote angiogenesis via sphingomyelin. Cancer Res. 2002; 62:6312-6317.

54. Zhou X, Arthur G. Improved procedures for the determination of lipid phosphorus by malachite green. $\mathrm{J}$ Lipid Res. 1992; 33:1233-1236. 